\title{
Preparation and characterization of thermoplastic elastomers (TPEs) based on waste polypropylene and waste ground rubber tire powder
}

\author{
Shu Ling Zhang, ${ }^{12}$ Zhen Xiu Zhang, ${ }^{1}$ Dong jin Kang, ${ }^{3}$ Dae Suk Bang, ${ }^{3}$ Jin Kuk Kim ${ }^{1 *}$ \\ ${ }^{1}$ School of Nano and Advanced Materials Engineering, Gyeongsang National \\ University, Gyeongnam, Jinju, 660-701, Korea Gyungbuk, Gumi, 730-701, Korea; tel: \\ (+82) (0)55-751-5299; fax: (+82) (0)55-753-6311; email: rubber@gsnu.ac.kr \\ ${ }^{2}$ Alan G. MacDiarmid Lab, College of Chemistry, Jilin University; Changchun, \\ 130012, People's Republic of China. \\ ${ }^{3}$ Department of Polymer Science and Engineering, Kumoh National Institute of \\ Technology.
}

(Received: 30 October, 2007; published: 10 December, 2008)

\begin{abstract}
In this article, the possibility of obtaining the recycled material based on waste polypropylene (WPP) and waste ground rubber tire powder (WGRT) has been studied. It has been proved that partially replacing WPP with PP-g-MA increased the elongation at break of WPP/WGRT blends, whereas decreased the thermal stability. The presence of compatibilizer increased the elongation at break and thermal stability of WPP/WGRT blends, whereas decreased the processing flowability, as revealed by using universal testing machine (UTM), scanning electron microscopy (SEM), thermogravimetric analysis (TGA) and capillary rheometer. Moreover, the tendency of the change became more obvious with the content of PP-g-MA and compatibilizer or with the combination of PP-g-MA and compatibilizer. In addition, the improvement of the nonpolar compatibilizer (SEBS) in properties of WPP/WGRT blends was better than that of the polar compatibilizer (SEBS-g-MA).

Keywords: TPE, waste polypropylene, waste ground rubber tire powder, compatibility
\end{abstract}

\section{Introduction}

The disposal of waste ground rubber tire and its economic recycling represent a great challenge because of the day-by-day increase in environmental awareness. The recycling and reutilization of waste ground rubber tire are difficult propositions because of the three-dimensional chemical network. This network renders the material insoluble and non-melting thus creating serious problems during reprocessing [1, 2].

Several methods have been suggested to recycle waste ground rubber tire but largescale utilization is hindered due to its high cost. A promising way of 'recycling' waste ground rubber tire powder (WGRT) is to incorporate it into thermoplastics to obtain thermoplastic elastomers (TPEs) and the perfect choice for thermoplastics is waste polypropylene (WPP) due to the lower cost. It is well known that the final properties of TPEs based on WGRT and thermoplastic depend on the nature of WGRT, the type of the matrix and the adhesion between WGRT and the polymer matrix [3-5]. 
In order to obtain the recycled material with good properties based on WGRT, some authors converted vulcanized rubber powder into usable rubber products by using ultrasonic waves and high-pressure high-temperature sintering [6-8], while other authors utilized the modified polymers as compatibilizer to improve the adhesion between WGRT and the polymer matrix $[9,10]$. The objective of this work is to prepare thermoplastic elastomers based on waste polypropylene and waste ground rubber tire powder in the presence of PP-g-MA and compatibilizer and discuss the influence of the content of PP-g-MA and compatibilizer on the mechanical, thermal and rheological properties of WPP/WGRT blends.

\section{Results and discussion}

\section{Mechanical properties of WPP/WGRT blends}

One of major criteria for a thermoplastic elastomer is that elongation at break is more than $100 \%$. This is the primary reason why we focus on the tensile mechanical response of blends in this work and the influence of PP-g-MA and compatibilizer on the tensile mechanical properties of blends is shown in Table 1.

Tab. 1. The average values of tensile mechanical properties of WPP/WGRT blends.

\begin{tabular}{llcc}
\hline Sample & \multicolumn{1}{c}{ Composition } & $\begin{array}{c}\text { Tensile } \\
\text { strength } \\
(\mathrm{MPa})\end{array}$ & $\begin{array}{c}\text { Elongation } \\
(\%)\end{array}$ \\
\hline 1 & Waste PP/WGRT=50/50 & 12.4 & 95.7 \\
2 & Waste PP/PP-g-MA/WGRT=25/25/50 & 12.0 & 125.7 \\
3 & PP-g-MA/WGRT=50/50 & 11.0 & 153.7 \\
4 & Waste PP/WGRT/SEBS=50/50/5 & 11.7 & 133.5 \\
5 & Waste PP/WGRT/SEBS =50/50/10 & 10.7 & 177.3 \\
6 & Waste PP/WGRT/SEBS =50/50/20 & 10.1 & 237.7 \\
7 & Waste PP/WGRT/SEBS-g-MA=50/50/20 & 11.1 & 200.3 \\
8 & Waste PP/PP-g- & 9.2 & 299.3 \\
9 & MA/WGRT/SEBS=25/25/50/20 & & \\
9 & Waste PP/PP-g-MA/WGRT/SEBS-g- & 10.3 & 270.0 \\
\hline
\end{tabular}

From Table 1, it can be seen that the elongation of the blends gradually increases with the amount of waste PP substituted by PP-g-MA, whereas the tensile strength of the blends gradually decreases. This may be due to the nature and the compatibilized effect of the added PP-g-MA. Namely PP-g-MA has a certain extent compatibility with PP but also MA group in PP-g-MA can react with phenolic $\mathrm{OH}$ group in WGRT [11]. The outcome is that the interface adhesion or the compatibility between WGRT and WPP can be improved with the amount of waste PP substituted by PP-g-MA.

From Table 1, it can also be seen that the elongation of the blends gradually increases with the content of SEBS, whereas the tensile strength of the blends gradually decreases. This may be ascribed to the nature and the compatibilized effect of the added SEBS. Namely SEBS has a certain extent compatibility with WPP and WGRT due to the repulsion effect of ethylene and butylene segments [11]. As a consequence the interface adhesion or the compatibility between WGRT and WPP 
can be enhanced with the content of SEBS. In addition, the improvement of the nonpolar compatibilizer (SEBS) in elongation at break of WPP/WGRT blend was better than that of the polar compatibilizer (SEBS-g-MA), which may result from the state of compatibilizer. SEBS is powder, whereas SEBS-g-MA is granule. SEBS could better achieve the dispersion in waste ground rubber tire powder than SEBS-gMA during premix. Therefore, the more effective interface between waste ground rubber tire powder and waste propylene could be obtained for SEBS.

The combination of PP-g-MA and SEBS or PP-g-MA and SEBS-g-MA can increase the MA amount of the system so as to further improve the interface adhesion between waste propylene and waste ground rubber tire powder. From Table 1, it can be seen that the blends using combination of PP-g-MA and SEBS or PP-g-MA and SEBS-g-MA exhibit the higher elongation at break compared with the blends using PP-g-MA, SEBS and SEBS-g-MA alone. Therefore the improvement of combination of compatibilizer and PP-g-MA in the elongation at break of WPP/WGRT blends is the most significant, followed by compatibilizer or PP-g-MA alone, as supported by SEM micrographs in Fig 1a-1d.

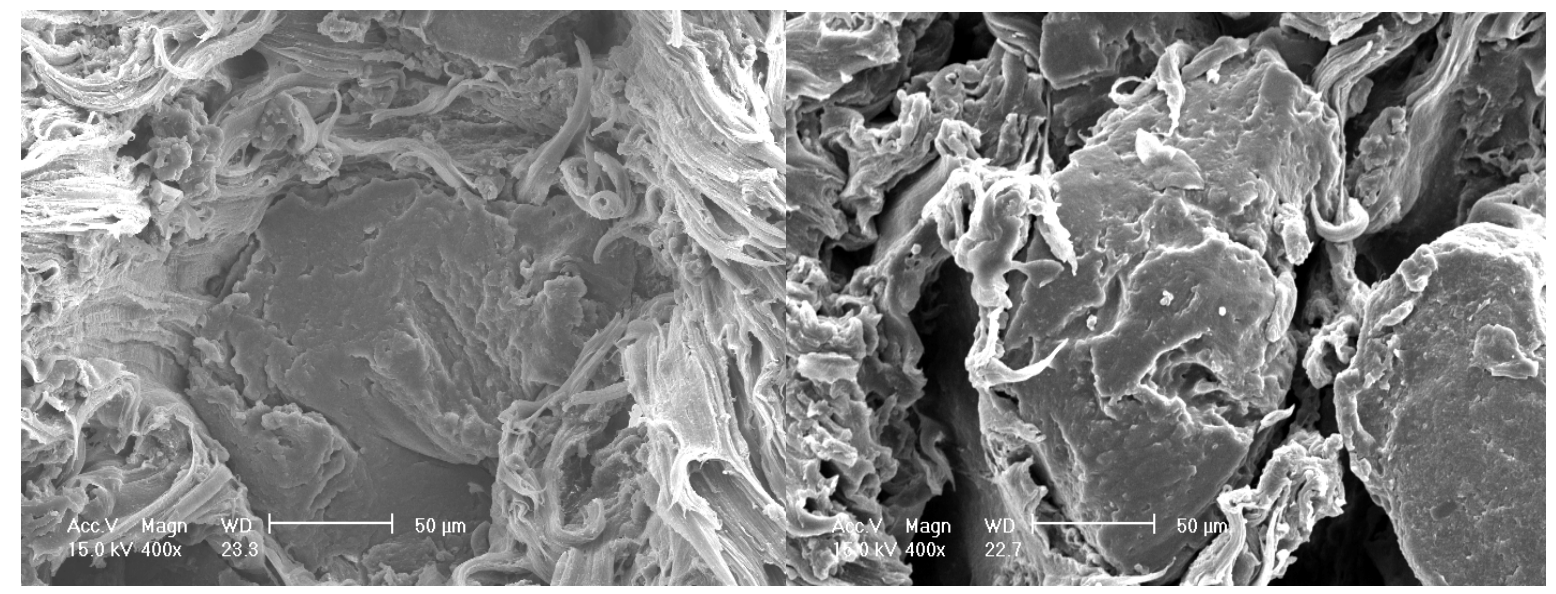

(a)

(b)

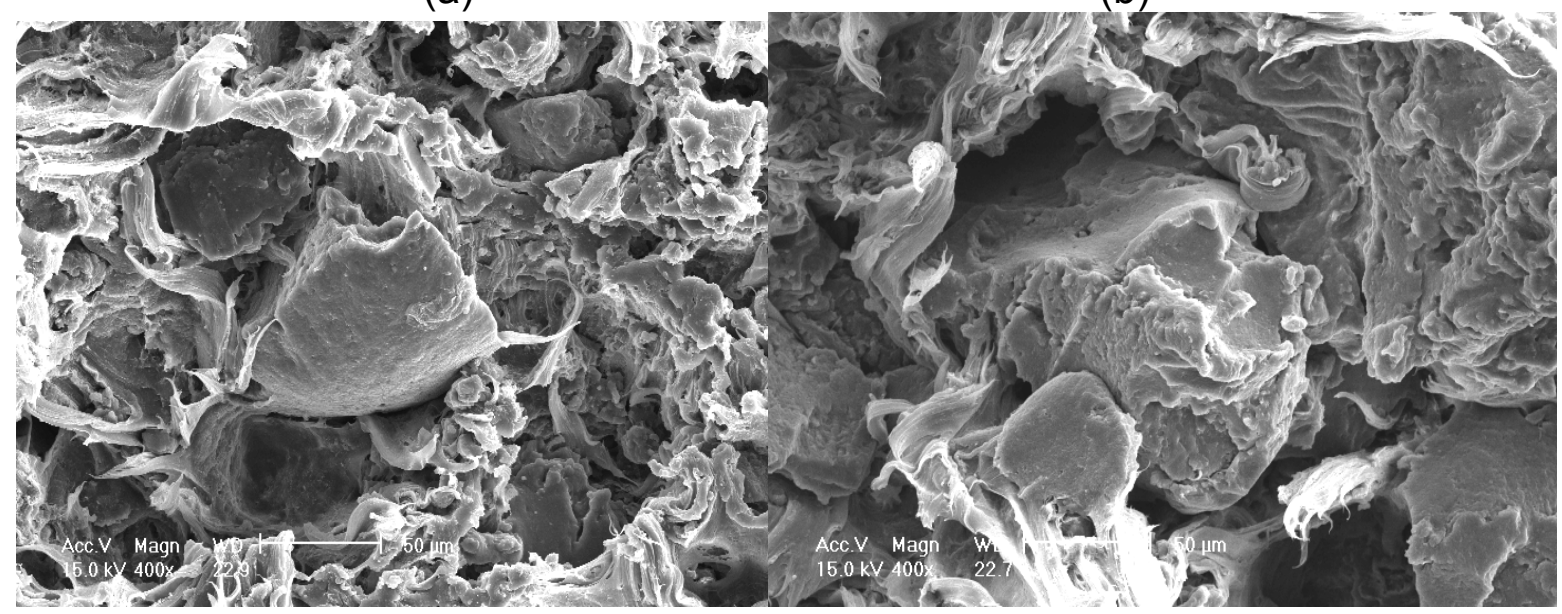

(c)

(d)

Fig. 1. SEM micrographs of the fracture surface for the blends after tensile measurement: (a) waste PP/PP-g-MA/WGRT/SEBS $=25 / 25 / 50 / 20$, (b) waste PP/WGRT/SEBS=50/50/20, (c) waste PP/PP-g-MA/WGRT=25/25/50, (d) waste PP/WGRT $=50 / 50$. (Scale bar is $50 \mu \mathrm{m}$ ). 


\section{Thermal stability of WPP/WGRT blends}

The $5 \%$ weight loss temperature $\left(T_{5 \%}\right)$ and the peak degradation temperatures $\left(T_{p}\right)$ of all materials are given in Table 2. It can be found that the presence of PP-g-MA decreases the thermal stability of the blend due to the worse thermal stability of PPg-MA in comparison with waste PP, while the presence of SEBS increases the thermal stability of the blend due to the better thermal stability of SEBS in comparison with WPP/WGRT (50/50) blend and the better compatibility between WGRT and WPP. Moreover, the tendency of the change becomes more obvious with the content of PP-g-MA and SEBS. It is noticeable that the improvement of the nonpolar compatibilizer (SEBS) in thermal stability of WPP/WGRT blend was better than that of the polar compatibilizer (SEBS-g-MA). This may also origin from the above reason, namely the presence of the more effective interface. An effective interface can better implement the improvement in properties. Therefore the thermal stability of WPP/WGRT blends decreases in the order of compatibilizer alone (sample 4, 5 and 6) > combination of compatibilizer and PP-g-MA (sample 7 and 8) > without compatibilizer and PP-g-MA (sample 1)> PP-g-MA alone (sample 2 and 3).

Tab. 2. The $5 \%$ weight loss temperature $\left(T_{5 \%}\right)$ and the peak degradation temperatures $\left(T_{p}\right)$ of all materials.

\begin{tabular}{llcc}
\hline Sample & \multicolumn{1}{c}{ Composition } & $\mathrm{T}_{5 \%}\left({ }^{\circ} \mathrm{C}\right.$ & $\mathrm{Tp}\left({ }^{\circ} \mathrm{C}\right)$ \\
& & & \\
\hline 1 & Waste PP/WGRT=50/50 & 317 & 441 \\
2 & Waste PP/PP-g-MA/WGRT=25/25/50 & 312 & 441 \\
3 & PP-g-MA/WGRT=50/50 & 305 & 436 \\
4 & Waste PP/WGRT/SEBS=50/50/5 & 319 & 453 \\
5 & Waste PP/WGRT/SEBS =50/50/20 & 326 & 458 \\
6 & Waste PP/WGRT/SEBS-g-MA=50/50/20 & 321 & 451 \\
7 & Waste PP/PP-g- & 322 & 447 \\
& MA/WGRT/SEBS=25/25/50/20 & & \\
8 & Waste PP/PP-g-MA/WGRT/SEBS-g- & 317 & 447 \\
9 & MA=25/25/50/20 & 306 & 376 \\
10 & Waste PP & 247 & 328 \\
11 & PP-g-MA & 410 & 465 \\
12 & SEBS-g-MA & 375 & 452 \\
\hline
\end{tabular}

\section{Rheological properties of WPP/WGRT blends}

Plots of shear stress versus shear rate for the blends at $200{ }^{\circ} \mathrm{C}$ are exhibited in Fig 2 . It can be seen that the addition of PP-g-MA does not change the shear viscosity of waste PP/WGRT blends due to the common effect, namely the nature of the added PP-g-MA decreases the shear viscosity of waste PP/WGRT blend, whereas the enhanced compatibility between waste PP and WGRT increases the shear viscosity of waste PP/WGRT blend. It can also be seen that the addition of SEBS or SEBS-gMA slightly increases the shear viscosity of waste PP/WGRT blends due to the compatibilized effect. Therefore the shear viscosity of WPP/WGRT blends decreases in the order of compatibilizer alone $\approx$ combination of compatibilizer and PP-g-MA > PP-g-MA alone $\approx$ without compatibilizer and PP-g-MA. 

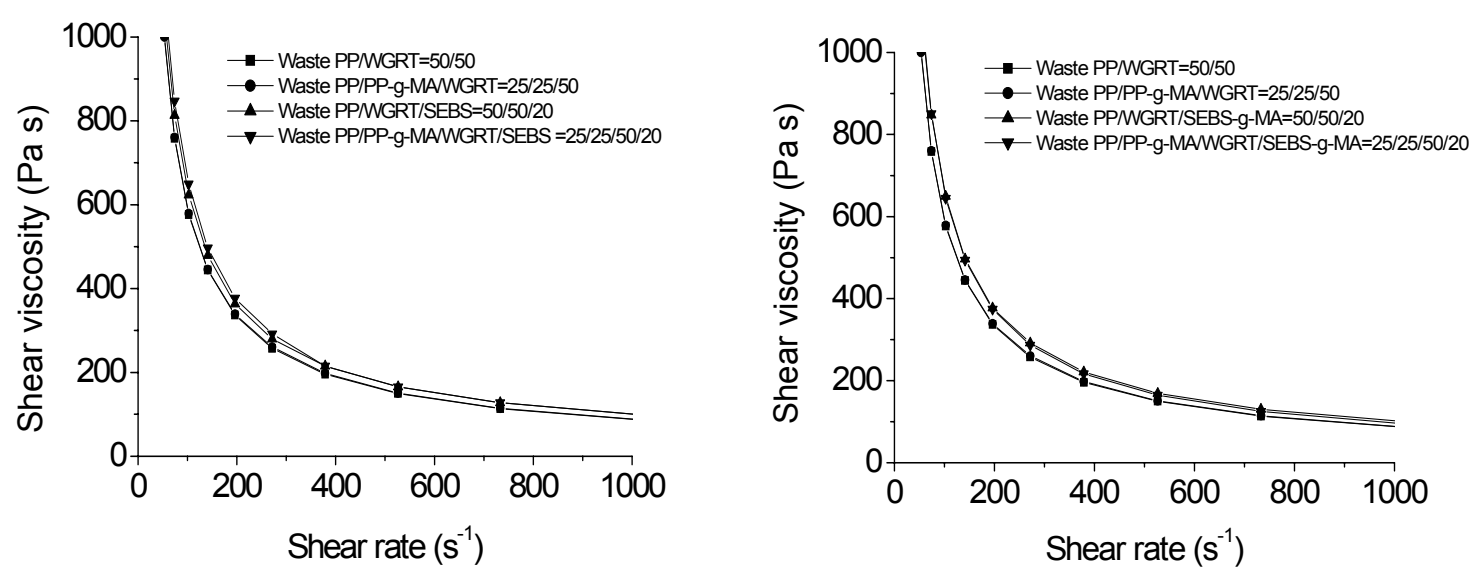

Fig. 2. Plots of shear stress versus shear rate for the composites at $200{ }^{\circ} \mathrm{C}$.

\section{Conclusions}

In this article, the possibility of preparing thermoplastic elastomers based on waste polypropylene (WPP) and waste ground rubber tire powder (WGRT) has been studied. It has been proved that the improvement of combination of compatibilizer and PP-g-MA in the elongation at break of WPP/WGRT blends is the most significant, followed by compatibilizer or PP-g-MA alone. The thermal stability of WPP/WGRT blends decreases in the order of compatibilizer alone $>$ combination of compatibilizer and PP-g-MA > without compatibilizer and PP-g-MA > PP-g-MA alone. Moreover, the shear viscosity of WPP/WGRT blends decreases in the order of compatibilizer alone $\approx$ combination of compatibilizer and PP-g-MA > PP-g-MA alone $\approx$ without compatibilizer and PP-g-MA. The change in properties should be attributed to the nature of the addition and the change in compatibility. From the view of obtaining recycled material with the higher elongation at break, better thermal stability and smaller shear viscosity, the combination of compatibilizer and PP-g-MA certainly is an attractive alternative to prepare TPEs based on WPP and WGRT.

\section{Experimental}

\section{Materials}

Waste polypropylene (WPP) was obtained from Korea TR Co. Ltd. Styrene-ethylenebutylene-styrene (SEBS, Kraton G1652) and maleic anhydride-grafted styreneethylene-butylene-styrene (SEBS-g-MA, Kraton FG-1901X) were manufactured by Shell Chemical Co. Ltd. Maleic anhydride-grafted polypropylene (PP-g-MA) was supplied by the lab of Prof. Bang. Waste ground rubber tire powder (WGRT) was produced by wet grinding method and was supplied by Hongbok Industries in Korea. The composition of WGRT was polymer content of $48.5 \%$ with natural rubber (NR) and styrene-co-butadiene rubber (SBR) in $25 \%$ and $75 \%$ ratio respectively. The other composition of WGRT was organic additive, carbon black and ash content of $13.4 \%$, $27.7 \%$ and $10.4 \%$ respectively.

\section{Sample preparation}

The blends were prepared in a L40/D19 twin-screw extruder at the screw speed of $100 \mathrm{rpm}$ and temperature profile of $160 / 190 / 210 / 220 / 220 / 230 / 230 / 225{ }^{\circ} \mathrm{C}$ as well as molded at temperature profile of $230 / 240 / 240 / 250{ }^{\circ} \mathrm{C}$ by injection. 


\section{Sample characterization}

The tensile properties of the dumbbell samples were measured using a Lloyd LR10K tensile testing machine, with crosshead speed of $500 \mathrm{~mm} / \mathrm{min}$, and the average value of mechanical properties was calculated using at least 5 samples. The thermal decomposition was performed by thermogravimetric analyzer (DuPont instrument, TA2100) in nitrogen atmosphere at a rate of $10{ }^{\circ} \mathrm{C} / \mathrm{min}$. The rheological properties were carried out using a capillary rheometer (Kayeness Inc. USA, model Galaxy V8052) at $200{ }^{\circ} \mathrm{C}$. SEM micrographs of fracture surface of all samples after tensile measurement were obtained using a model Philips XL-30S scanning electron microscope and the surfaces of all samples were coated by a thin gold layer.

\section{Acknowledgements}

The authors acknowledge the support from the BK21 program in Korea.

\section{References}

[1] Rajalingam, P.; Baker, W. E. Antec' 92 1992, p799.

[2] Adhikari, B.; De, D.; Maiti, S. Prog Polym Sci 2000, 25, 909.

[3] De, S. K.; Bhowmick, A. K. editors. Thermoplastic elastomers from rubber-plastic blends. Chichester: Ellis Horwood; 1990.

[4] Rajalingam, P.; Shape, J.; Baker, W. E. Rubber Chem Technol 1993, 66, 664.

[5] Karger-Kocsis, J. Thermoplastic rubber via dynamic vulcanization. In: Shonaike G. O., Simon G. P., editors. Polymer blends and alloys. New York: Marcel Dekker; 1999, p125.

[6] Isayev, A. I.; Chen, J.; Tukachinsky, A. Rubber Chem Technol 1995, 68, 267.

[7] Hong, C. K.; Isayev, A. I. J. Appl. Polym. Sci. 2002, 83, 160.

[8] Tripathy, A. R.; Morin, J. E.; Williams, D. E.; Eyles, S. J.; Farris, R. J. Macromolecules 2002, 35, 4616.

[9] Naskar, A. K.; Bhowmick, A. K.; De, S. K. Polym. Eng. Sci. 2001, 41, 1087.

[10] Rajalingam, P.; Baker, W. E. Rubber Chem Technol 1992, 65, 908.

[11] Lee, S. H.; Balasubramanian, M.; Kim, J. K. J. Appl. Polym. Sci. 2007, 106, 3209 . 